\title{
Nodes and arcs: concept map, semiotics, and knowledge organization
}

\author{
Alon Friedman \\ New York, New York, USA, and \\ Richard P. Smiraglia \\ Information Organization Research Group, School of Information Studies, \\ University of Wisconsin-Milwankee, Milwankee, Wisconsin, USA
}

\begin{abstract}
Purpose - The purpose of the research reported here is to improve comprehension of the socially-negotiated identity of concepts in the domain of knowledge organization. Because knowledge organization as a domain has as its focus the order of concepts, both from a theoretical perspective and from an applied perspective, it is important to understand how the domain itself understands the meaning of a concept.

Design/methodology/approach - The paper provides an empirical demonstration of how the domain itself understands the meaning of a concept. The paper employs content analysis to demonstrate the ways in which concepts are portrayed in KO concept maps as signs, and they are subjected to evaluative semiotic analysis as a way to understand their meaning. The frame was the entire population of formal proceedings in knowledge organization - all proceedings of the International Society for Knowledge Organization's international conferences (1990-2010) and those of the annual classification workshops of the Special Interest Group for Classification Research of the American Society for Information Science and Technology (SIG/CR).

Findings - A total of 344 concept maps were analyzed. There was no discernible chronological pattern. Most concept maps were created by authors who were professors from the USA, Germany, France, or Canada. Roughly half were judged to contain semiotic content. Peirceian semiotics predominated, and tended to convey greater granularity and complexity in conceptual terminology. Nodes could be identified as anchors of conceptual clusters in the domain; the arcs were identifiable as verbal relationship indicators. Saussurian concept maps were more applied than theoretical; Peirceian concept maps had more theoretical content.

Originality/value - The paper demonstrates important empirical evidence about the coherence of the domain of knowledge organization. Core values are conveyed across time through the concept maps in this population of conference papers.
\end{abstract}

Keywords Concept maps, Semiotics, Knowledge organization, SIG/CR, ISKO, Peirce, Saussure, Nodes, United States of America, Germany, France, Canada

Paper type Research paper

\section{On concepts and meaning}

The concept has a central role not only in knowledge organization but in information science in general. How ironic, then, that there should be a central entity with no fixed definition - a dichotomy that unfortunately infuses central tenets of both knowledge organization and information science. Recent scholarship by Hjørland (2009) surveyed different views of concepts showing that they often "are associated with different world-views and epistemologies ... which tend to compete with each other" (p. 1,519). Hjørland's review concludes that the concept is a socially negotiated construct that
Received 19 May 2011

Revised 17 April 2012

Accepted 19 April 2012

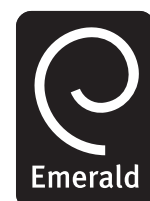

Journal of Documentation Vol. 69 No. 1, 2013 pp. $27-48$

(C) Emerald Group Publishing Limited 0022-0418 


\section{JDOC 69,1}

28 should be identified by studying discourses (p. 1,530). Stock (2010) synthesizes various approaches to the definition of a concept, suggesting multiple epistemological points-of-view compete in information science, but two sorts of definition, which he calls "concept explanation and family resemblance" predominate in the design of information systems (p. 1,966). More recently, Friedman and Thellefsen (2011, p. 665) reported on the emergence of concept theory and semiotics in knowledge organization under the definition of the term "knowledge organization systems" (see Hodge, 2000). Using two components - the relationship of the concept and the classification of the concept - Friedman and Thellefsen outlined Dahlberg's concept theory as it captures concept representation. A closer look at Dahlberg's concept triangulation revels that the terms "reference," "characteristics," and "verbal form," required more in-depth discussion on the terms representation and knowledge presentation. Furthermore, they reported that knowledge organization as a domain has as its focus the order of concepts, both from a theoretical perspective and from an applied perspective. Therefore, it is important to understand how the domain's authors understand the meaning of a concept found in text and its visual maps. The purpose of the research reported here is to improve comprehension of the socially-negotiated identity of concepts in the domain of knowledge organization. Nevertheless, knowledge organization as a domain has as its focus the order of concepts, both from a theoretical perspective and from an applied perspective. Therefore, it is important to understand how the domain's authors understand the meaning of a concept.

Semiotic analysis has played a very important role in the scholarship of knowledge organization for this reason - that is, semiotic analysis has helped the theoretical advancement of the order of concepts by providing parameters for "meaning." Semiotics is the study of the meaning of language, its reasoning, and its relationship to the world. In particular, during the nineteenth century, two schools of thought emerged, each providing a different interpretation of the "sign." American philosopher Charles Sanders Peirce offered a "triadic" foundation of the sign, whereas Swiss linguist Ferdinand de Saussure had a "dyadic," or two-part, structure to the "sign." Semiotic analysis has played a prominent role in knowledge organization research, and so we offer as background a thorough review of semiotic theory from the point-of-view of KO scholarship.

Concept maps - illustrations that show the relationship among concepts in graphic form - are often used as a tool for learning the meaning of concepts by allowing the creator of the map to provide a specific visual interpretation. Knowledge organization (KO) is no stranger to the concept map; such particular illustrations are used extensively in conference papers in the domain. In fact, it is possible to consider the concepts portrayed inside KO concept maps as signs, and subject them to semiotic analysis as a way to understand their meaning. In this way, semiotics can provide the ability to analyze the relationships that scholars in KO create in their own maps. This paper reports a research project in which all concept maps in two series of KO conference proceedings were subjected to evaluative semiotic analysis to observe patterns employed in the use and meaning of concepts by KO researchers. We begin this report with an overview of the term "concept" and of its visualization, particularly through "concept maps." This we follow with analysis of the use of semiotics in KO. We describe an empirical analysis of specific concept maps and the concepts represented in them. We conclude with a discussion about concepts, meaning, and their union in concept maps, in the domain of knowledge organization. 


\subsection{About the term "concept"}

According to Margolis and Laurence (2005), the term "concept" has become one of art among philosophers because of the diversity of concerns with which it is associated. Adding to the confusion is the fact that the term causes dispute among philosophers, often reflecting deeply opposing positions. The two philosophy schools in conflict here are the analytic school and the postmodern deconstructionist one, thus pitting the study of logic and philosophy of language (the analytic school) over against the deconstruction of texts. Frege (1892) made a distinction between concept and object, by defining a concept as a function that has a truth-value. An object's value for an argument can be either of the abstract objects "the True" or "the False." According to Frege, the concept being human is understood as a function that has "the True" as value for any argument that is human, and "the False" as the value for everything else. In Frege's terminology, an object for which a concept has value "the True" is said to "fall under" the concept. Any sentence that expresses a singular proposition is an expression. The singular proposition is addressed by a proper name or a general term: that definite article that signifies an object together with a predicate. According to Frege, along with a verb, the concept is signified by the general term accompanied by the indefinite article, or an adjective. According to Tarski (1995), this distinction was of fundamental importance in the development of logic and mathematics.

Using Frege's framework, Peacocke (1999) established his own theory of concepts. He defined them as constituents of contents that are associated with singular expressions and logical expressions as well as with predicates. According to Peacocke (1999, p. 2), a concept can be individuated by providing the conditions a thinker must satisfy in order to possess that concept:

Concepts $\mathrm{C}$ and $\mathrm{D}$ are distinct if and only if there are two complete propositional contents that differ at most in that one contains $\mathrm{C}$ substituted in one or more places for $\mathrm{D}$, and one of which is potentially informative while the other is not.

In other words, $\mathrm{C}$ and $\mathrm{D}$ embody differing modes of presentation. For Peacocke, the account of a given concept is based on its semantic value, which determines the theory of the concept.

In contrast to the analytic approach, which addresses a term's value, Barthes (1975), using the postmodern and deconstructionist framework, looks at how language manipulates society's ideology. He defines myth as a reference to the theory of second-degree sign systems and semiotics. More specifically, he looks at the uses of special language, distinguishing the mythic system from language per se, and makes a distinction between "signify" and "signifier" with regard to myth. (The meaning of signifiers will be discussed more fully below). To "signify" is to represent; a "signifier" is a perception of a representation. For Barthes, the signified is the concept, and the signifier is the acoustic image based on Saussure's (1916/1983) definition. Myth, Barthes explains, encompasses photography, films, reporting, shows, and publicity. In his later works Barthes defined the term differently and each time in a different context. "Myth" is defined as a traditional story accepted as history (Webster's Dictionary, 1984, p. 785), which serves to explain the world view of a people. According to Gaines (2002), semiotics offered specialized tools to address the problem of explaining the term "myth." Gaines saw semiotics as a unique theoretical position that 


\section{JDOC 69,1}

can serve to draw together linguistic, cognitive, philosophical, historical, social, and cultural perspectives, unlike any other frameworks.

\subsection{On concept "maps"}

A "map" can be defined as a representative act, and the process of making graphic representation (Webster's Dictionary, 1984, p. 725). "Concept mapping" is a term said to have been developed by Novak and Gowin (1984), though in fact it was employed as early as the 1930s. The technique has provided visual representations of knowledge structures in academic and business settings since the late 1980s. Novak and Gowin defined it using three key terms: concept, proposition, and learning. According to these theorists, the label for most concepts is a single word, although sometimes we use symbols such as " + " or "\%." Propositions are statements about some object or event in the universe. They can be either naturally occurring or constructed. They contain two or more concepts connected with other words to form a meaningful statement. Sometimes these are called semantic units, or units of meaning. The term "learning," according to Novak and Gowin, stresses the important role of prior knowledge in students' acquisition of new concepts. They explained that the representation of concepts and their relationships in graphical form provides a visually rich format for representing knowledge in different ways.

In general terms, concept maps can be considered sophisticated visual "signs." That is, concept mapping represents knowledge in the form of electronically monitored displays, as signs represent events or things that receive direct attention, or are indicative of other events or things. Concept maps consist of text and images, and links, which describe the relationship between the nodes and arcs. The nodes are labeled with descriptive text, representing the "concept," and the arcs represent the type of relationship between them. According to Lambiotte et al. (1984), the relationship between the nodes and arcs in the map represents the connection between knowledge and language. A relationship between the nodes and arcs can be directed or undirected between two nodes, just as we experience it in language. A directed relationship points from one node to another. As illustrated in Figure 1, two nodes labeled "Fruit" and "Tree" might have an arc between them called "grow on," with the arc directed from Apples to Trees, indicating that Apples grow on Trees.

In contrast to the short history of the term "concept mapping," the term "sign" has been the subject of long philosophical debates in the field of semiotics.

\subsection{Semiotics: on meaning, and signs}

Semiotics, the study of signs, is derived from philosophical speculations on signification and language (Chandler, 2004, p. 5). In the nineteenth century, deliberation on the meaning of the term continued in two schools of thought that provided different interpretations. One was promulgated by the American philosopher Charles Sanders Peirce, who proposed the study of the sign as "semeiosis." Peirce offered a triadic foundation of the term, where anything can be a sign as long as someone interprets it as signifying something, referring to, or standing for something other than itself (Peirce, 1931-1958, p. 2.302). Ferdinand de Saussure called the study of signs semiology - the study of the life of signs in society. He proposed a dyadic, or two-part, model of the term sign. The sign, according to Saussure, is made up of the signifier (the mark or sound) and the signified (the concept or idea). The terms cannot be conceptualized as 


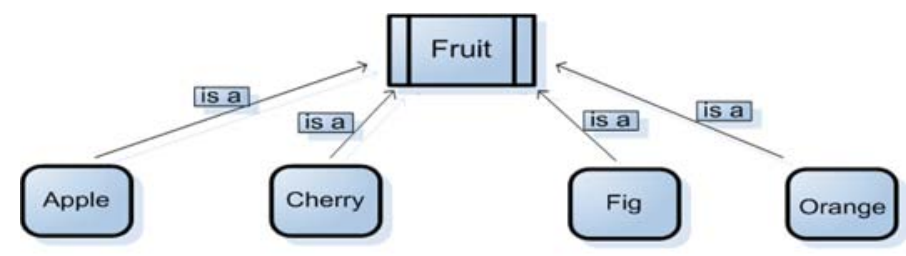

Nodes and arcs

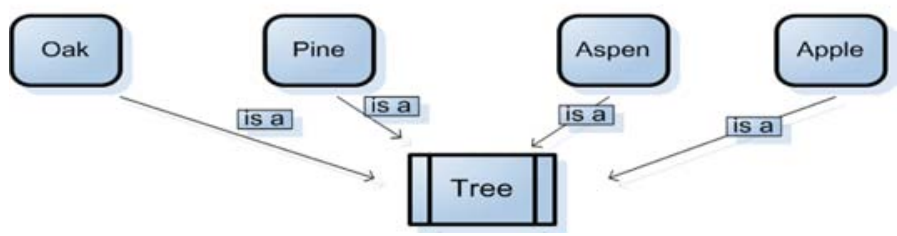

Figure 1.

A direct relationship between arcs and nodes in concept maps

separate entities, but rather as mapping from significant differences in the speech act. For Saussure, signs stand for something else, whereas language operates as a sound system of signs. According to Saussure, words are not merely names that represent things but are expressions that stand for some content. Peirce also discusses the terms signifier and signified, but for him, the theory is not about the language, but the production of meaning. Peirce uses a triangular model consisting of object-sign-interpretant. He maintains that a "sign" is anything that stands for something in somebody's mind. The signifier, for Peirce, stands for the Representamen, which is the form, not necessarily material in nature, that the sign takes. The signified for Peirce is the Object, which is that to which the sign refers. Peirce adds an additional element, the Interpretant, which is the sense made of the "sign" (Peirce, 1931-1958, p. 3.399).

The most important part of Peirce's philosophy and classificatory schema consists of his division of the conditions of signs. Peirce breaks the three main categories, which include Interpretant, Representamen, and Object, into (Peirce, 1931-1958, pp. 2.411, 2.432, 2.446):

(1) firstness - the mode of being of that which is such as it is, positively and without reference to anything in itself;

(2) secondness - the mode of being of that which is such as it is, with respect to a second but regardless of any third, which can be described as the representation or Vorstellung, a representation that is made by the perceiving subject of the object-in-itself; and

(3) thirdness - the mode of being of that which is such as it is, in bringing a second and third in relation to each other.

Peirce refers to the relationship between the object and the concept of it as a relationship that is expressed as a "sign." According to Peirce (1998, p. 2.483): 


\section{JDOC 69,1}

A sign or representamen is something that stands to somebody for something in some respect or capacity. It addresses somebody, which creates in the mind of that person an equivalent sign, or perhaps a more developed sign. That sign which it creates I call the interpretant of the first sign. The sign stands for something, its object. It stands for that object, not in all respects, but in reference to a sort of idea. The relation of an object which is in relation to its object on the one hand and to an interpretant on the other in such a way as to bring the interpretant into a relation to the object corresponding to its own relation to the object.

"Firstness" is the first awareness of a thing separated by our perception from the sensuous manifold. Its existence is either dependent on its being in the mind of some person, or in the form of sense or thought considered by that person. The next category is the "resistance," or an interruption of the initial awareness. This interruption, which calls us to an awareness of our state of awareness, is a Secondness. According to Mai (2001, p. 599), who cited Hoopes: "secondness is the dyadic mode which tells something about another object." Thirdness is the relationship between Firstness and Secondness; it is a relationship of linguistic signs. Meaning is not inherent, according to Peirce, but something one makes from signs. Expression - verbal, written, or otherwise - is the awareness of awareness, which is the Secondness of Firstness, a Thirdness.

Peirce also classified the Representamen, Interpretant, and Object to the Firstness, Secondness, and Thirdness sub-categories. These are:

- Representamen: Qualisign, Sinsign, Legisign.

- Interpretant: Argument, Dicent, Rheme.

- Object: Icon, Index, Symbol.

The Qualisign identifies a quality, the Sinsign a specific spatio-temporal thing or event, and a Legisign is a general idea, a law, a norm. The Argument is, as the name suggests, the reasoning behind the sign, the dicent is a logical proposition that establishes a relationship between constants, and the rheme is the object of firstness or secondness. The icon demonstrates the qualities of a "dynamical object," an index demonstrates the influence of its "dynamical object," and a symbol is a reference to its "dynamical object" that connects the Icon (Firstness) and Index (Secondness). Although Peirce provides many typologies of the sign, Chandler (2004) argues that we rarely mistake a representation for that for which it stands, especially when dealing with graphic representation. Christiansen (1988) and Chandler (2004) represent this relationship in a concept-mapping diagram (Figure 2) based on Peirce's theory.

Saussure (1983) examined the relationship between speech and the evolution of language, investigating language as a structured system of speech signs. He concentrated on the structure of language in which meanings are constituted by words exchanged in governed human speech systems, and offered a "dyadic," or two-part model, which consists of a signified and a signifier. For him, a "sign" is formed from the union of the signifier and the concept it represents. The connection between them is arbitrary and conventional, but only through their union are significant sounds and ideas articulated. Saussure's approach looks at the "sign" in terms of a single given timeframe, and, in a diachronic study, compares the same language at different times. Figure 3 represents Saussure's dyadic approach to the term "sign" (Chandler, 2004, p. 12). The relationship between the signified and signifier do not connect at any stage as illustrated in Saussure's dyadic map. 


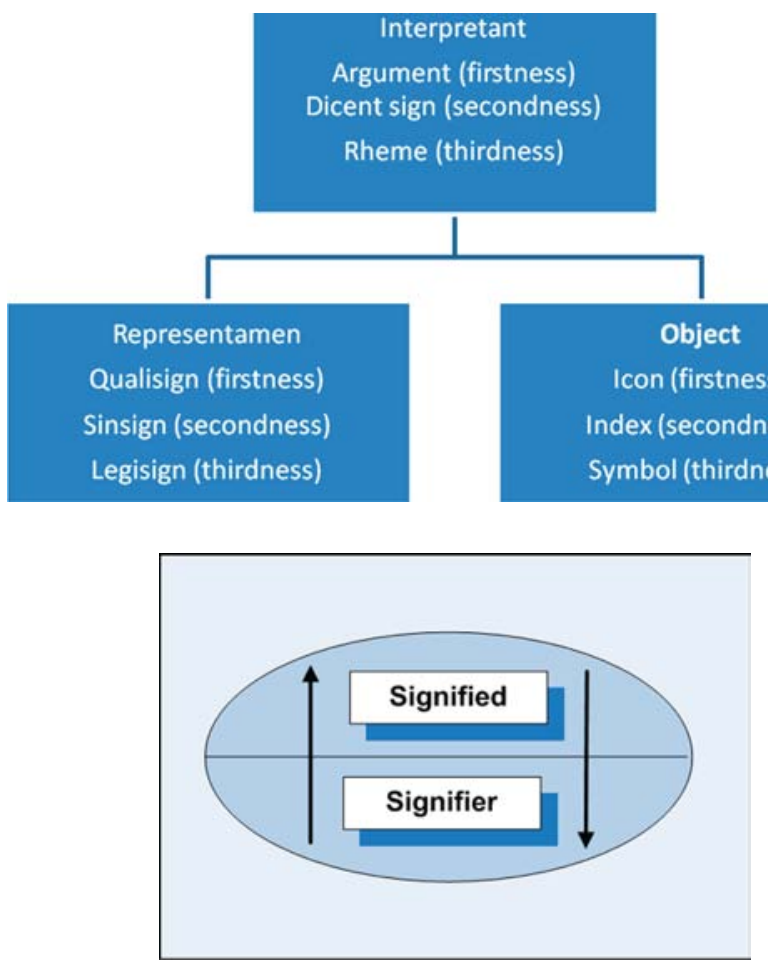

\section{Nodes and arcs}

Representamen

Qualisign (firstness)

Sinsign (secondness)

Legisign (thirdness)
Object

(firstness)

Index (secondness)

Symbol (thirdness)

Figure 3.

Saussure's dyadic semiotics approach to the term sign

This approach allows Saussure to examine two forms of rules:

(1) patterns existing in the system; and

(2) the linear nature of the signifier, which arises because "auditory signifiers have at their command only the dimension of time" (Saussure, 1983, p. 70).

"The signifier represents a span, which is measurable in a single dimension" (Chandler, 2004, p. 21) - that of time. Saussure draws a distinction between language (langue) and the activity of speaking (parole). For him, language is a system of signs that evolves from the activity of speech. It is a link between thought and sound, and provides a means for thought to be expressed as sound. In order for language to occur, thoughts have to become ordered, and sounds have to be articulated. For Saussure, a linguistic sign is a combination of a concept and a sound-image.

Meaning, in Saussure's theory, arises within the language system through relations of association and opposition (Saussure, [1916] 1983, p. 119 emphasis original):

Two signs, each comprising a signification and a signal, are not different from each other, but only distinct. They are simply in opposition to each other. The entire mechanism of language is based upon oppositions of this kind.

There are two types of relationships between the signifier and signified: syntagmatic and paradigmatic. The former operates through linear ordering and restriction (e.g. in the phrase "The department chair," the syntagmatic association of "department" 


\section{JDOC 69,1}

\section{4}

restricts the possible interpretations of "chair"). Paradigmatic relationships express similarities of sound or meaning between signs. In fact, signs acquire their meanings only through these structural relations (Saussure, 1983, p. 113):

A language is a system in which all the elements fit together, and in which the value of any one element depends on the simultaneous coexistence of all the others. In a given language, all the words which express neighboring ideas help define one another's meaning.

This, he goes on to say, applies not only to words, but also to sounds and more complex structures such as grammatical units.

The major difference between the two thinkers lies in the fact that Peirce examines how meanings and representations come about, while Saussure examines the structure of the system in which meanings and representations take place. That is, a Peircian question would be "how are meanings produced in an individual?" while a Saussurian one would be "what is the structure of language through which an individual finds himself to be represented as an individual?" (Sebeok, 1994, p. 157). Chandler (2004, p. 65) summarizes the differences between Peirce and Saussure with regard to the term "sign" as follows: the roles of spoken word vs the written, of the signifier and signified, of time and of language and its meaning. An additional major difference between Peirce and Saussure noted by Silverman (1983) is the contrast between content and representation. Peirce's classification is based on comparison (kind of sign), on performance (or ground of comparison) and on thought (or the kind of object that is being compared). Saussure (1983, p. 114), on the other hand, saw that 'language' has 'organized thought coupled with sound;' and 'each linguistic term is a member, an "articulus" in which an idea is fixed in a sound and a sound becomes the sign of an idea.'

\subsection{Signs and knowledge organization}

Knowledge organization is a domain concerned with the "ordering of what is known," particularly for information retrieval (Smiraglia, 2005). Numerous researchers in knowledge organization use Peirce's and Saussure's definitions of the term "sign" to support their particular foci of study. Many of them have studied the semiotic aspect of the sign with relation to meaning, key among them are Buckland, Mai, and Thellefsen. Buckland's (1997) work has been considered a milestone in the field. He made a distinction between the nature of the term "information" and the term "document." His definitions of the term "information" opened discussion on the role of language in the field of knowledge organization. He employed semiotic analysis to make the distinction between the two terms. Mai (2001) discussed the direct relationship between semiotics and indexing, maintaining that the process of indexing involves the interpretation and representation of documents: this activity is highly dependent upon social and cultural context. According to Mai, Peirce's theory is directly relevant to the manner in which the meanings of various words and expressions are produced in individual settings. He argued that Peirce's definition provides a more descriptive analysis of the process of indexing and classification that indexers must necessarily go through to achieve their objectives. Thellefsen $(2004,2006)$ studied the term "knowledge profile" in the field of organization. He defined it as a way to identify the epistemological basis, both scientific and nonscientific, of a domain. By using Peirce's framework, Thellefsen attempted to establish the term to provide a better understanding of the domain and allow users to better interact with the knowledge. 


\section{Methodology}

As we have seen, the concept is a central focus of knowledge organization. In order to comprehend the role of the concept it is important to understand meaning as well, thus we seek in the present study to provide an empirical demonstration of how the domain's authors understand the meaning of a concept. Concept maps - illustrations that show the relationship among concepts in graphic form - are frequent tools for providing visual interpretation in knowledge organization. Thus our objective was to consider the concepts portrayed in KO concept maps as signs, and subject them to evaluative semiotic analysis as a way to understand their meaning. Friedman (2006) reported a pilot study in which the concept maps found in the proceedings from two International Society for Knowledge Organization (ISKO) international conferences (2000 and 2004) were analyzed semiotically. Results indicated authors often used more than one strategy in the same paper; the Interpretant phase of Peirceian semiosis was little apparent, as was Thirdness.

For the present study our frame was the entire population of formal proceedings in knowledge organization. A general review of academic publications in the field (journals, conference proceedings, dissertations and monographs) revealed that concept maps appear more often in proceedings than in other formats. Thus we examined the proceedings of the International Society for Knowledge Organization's international conferences (1990-2010) and those of the annual classification workshops of the Special Interest Group for Classification Research (SIG/CR) of the American Society for Information Science and Technology. The last printed publication of the SIG/CR was from the conference held in Philadelphia, PA on November 17, 2002; no conference proceedings exist for the years 2003-2005; electronic proceedings were available on dList for 2006-2009. The study was exploratory, to answer the question: Can the term "sign" and its classification (as envisioned by Peirce and Saussure in terms of signified and signifier vs object-sign-interpretant) be applied to the concept maps found in ISKO and SIG/CR conference proceedings? A secondary question is: what can we learn from the use of concept maps about the meaning of the concept in the domain of knowledge organization?

Two operational definitions were developed to guide this study. These were:

(1) A concept map was defined in this study as a visual representation of the relationship between concepts. In order for a map to be counted in the study, the map needed to hold nodes and arcs. The nodes are represented by text, an image or links, which describe the "concept." The arcs represented the relationship between the "concepts."

(2) We analyzed the concept maps for "signs" according to both Peirceian and Saussurian definitions. A Peirceian "sign" is triadic, composed of Representamen, Object and Interpretant. The Representamen stands for the form, not necessarily material in nature, which the sign takes. The Object is what the sign refers to, while the Interpretant is the sense made of the "sign." A Saussurian "sign" is "dyadic," a two-part model that consists of "signifier," the form that the sign takes, and "signified," the concept it represents in the spoken language.

By examining the concept maps from both perspectives we were able to raise additional questions involving the terminology the researchers employed in their concept maps. 


\section{JDOC 69,1}

36

Figure 4.

A Peirceian concept map
Our principal method was content analysis. We examined the entire contents of both sets of conference papers to record demographic data, such as the country and occupational role of the authors using concept maps. Then, working with the concept maps themselves, we attempted to identify and classify the concepts found in the maps according to the Peirceian or Saussurian definitions of "sign." We first analyzed the major concepts we found in each and every map. In order for a map to count in the study, the map had to hold Nodes and Arcs. The Node had to be captured by text, image, and links that illustrate the relationship between other nodes in the map, and had to capture the anchors of conceptual clusters in the very same map. The Arcs represent the type of relationship between the nodes, serving as verbal relationship indicators. This definition of the term concept maps was given by Lambiotte et al. (1984). Furthermore, Baker et al. (1991) reported that concept maps that can be identified by their arcs and nodes allow students to easily recognize key concepts of any narrative's headings.

Our next step was to apply simple content analysis where our referral units consisted of three groups: Peirce, Saussure and others. Under the Peirceian triadic classification, the map's central node had to contain three arcs that exemplified Representamen, Object and Interpretant. As we have already explained earlier, the Representamen stands for the form, not necessarily material in nature, which the sign takes; the Object is that to which the sign refers, while the Interpretant is the sense made of the "sign." Figure 4 is an example of a Peirceian classification taken from Kent (2000, p. 117) where the sign in the map captures the conceptual understanding of knowledge organization. In this map "Logic" is the central point of the map but it also answers the call by Perican's Representamen, "Theory," is the Interpretant, and "Classification" is the Object.

Under a Saussurian "sign," the central sign found in the maps had to be "dyadic," consisting of "signifier," the form that the sign takes, and "signified," the concept it represents in the spoken language. Figure 5 is an example of Saussurian classification (Kent, 2000, p. 111) where the sign is the common generic extension of ontology shared between communities.

By employing Peirce's and Saussure's theories to classify concept maps, we hoped to discover clues to the specific conceptual processes that authors use in creating concept maps as well as to identify the socially-negotiated identity of concepts found in concept mapping in the domain of knowledge organization.

In the text that follows, we wish to remind our readers that we are working with the entire population of articles in the two series of conference proceedings, and thus not with a sample. Therefore, similarities and differences observed are significant and generalizable to the entire population under study, but not beyond. On the other hand,

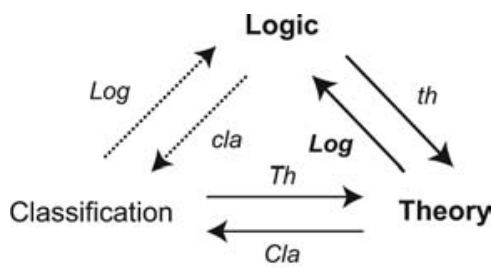

Source: Kent (2000, p. 117) 


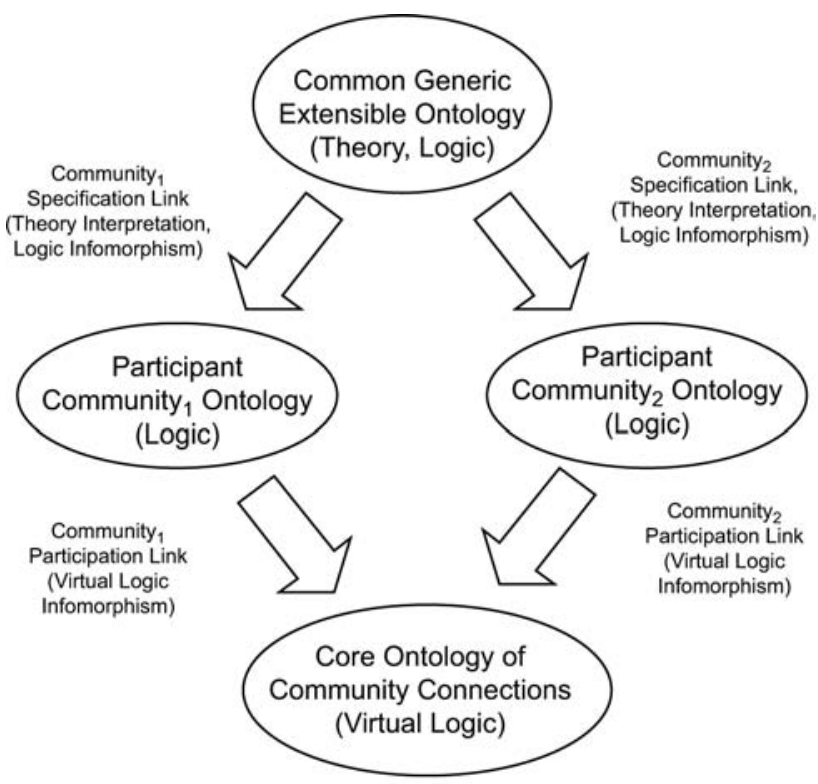

Source: Kent (2000, p. 111)
Nodes and arcs

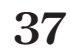

Figure 5. A Saussurian concept map

we are now working with a "sample;" so no specific measure of statistical significance is appropriate. In using Chi-squared to test various hypotheses, we are reporting a statistic that tells us that, with 90 percent confidence, the results are not likely chance.

\section{Results}

\subsection{Overview}

We reviewed a total of 344 concept maps, 128 from SIG/CR and 216 from ISKO. We looked first at the chronological distribution of concept maps. The number of concept maps found in ISKO proceedings ranged from 11 to 31 with no discernible chronological pattern. The largest numbers of concept maps were used in 1998, 2006 and 2010, and the lowest numbers in 1996, 1990 and 1994. The numbers of concept maps in SIG/CR proceedings varied more, ranging from 1 in 1997 to 18 in 1993 and 17 in 1994. Otherwise there was again no particularly discernible chronological pattern. Figure 6 shows a visualization of the chronological distribution over the 19-year span.

We were curious to know whether there was any difference in the use of concept maps by authors from different parts of the world, or by authors with different professional responsibilities. Using the authors' bylines in the conference papers we categorized their countries of affiliation and their occupational roles (professor, practitioner, and student). In the ISKO proceedings, most concept maps were produced by authors from the USA, Germany and France, although 23 countries were counted. In the SIG/CR proceedings, most concept maps were produced by authors from the USA by a wide margin (65.6 percent), followed by France and Canada; ten countries were counted. The combined geographical distribution is illustrated in Table I. Most concept maps were contributed by authors from the USA, Germany, France, and Canada. 


\section{JDOC}

69,1

\section{8}

Figure 6.

Chronological distribution of concept maps visualized

\section{Number of concept maps}

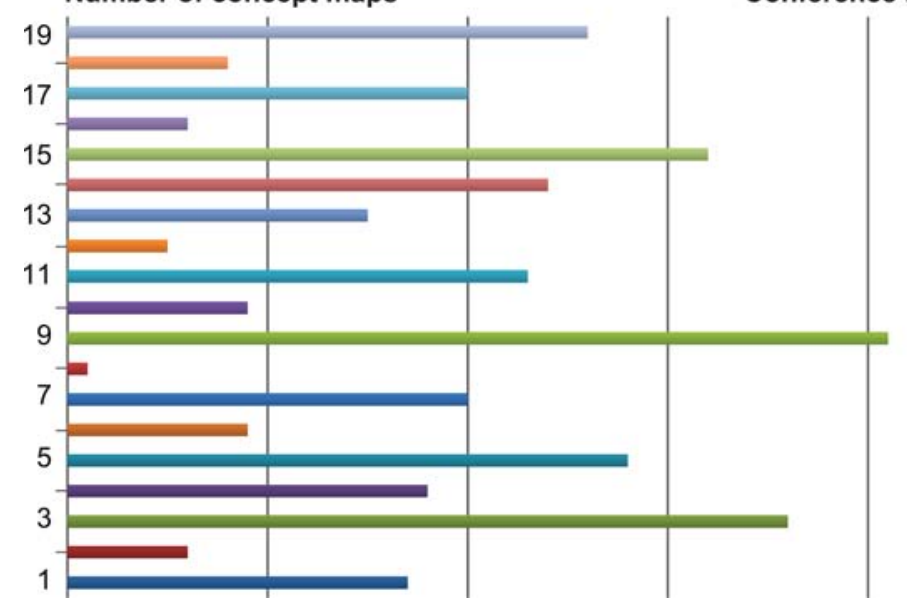

Conference Proceedings

1990

1992

1994

1996

1998

2000

2002

2004

2006

2008

2010

\begin{tabular}{lrr}
\hline Country & Frequency & Percent \\
\hline USA & 135 & 39.2 \\
Germany & 44 & 12.8 \\
France & 43 & 12.5 \\
Canada & 23 & 6.7 \\
UK & 20 & 5.8 \\
Denmark & 9 & 2.6 \\
Finland & 9 & 2.6 \\
Spain & 9 & 2.6 \\
Sweden & 8 & 2.3 \\
Italy & 7 & 2.0 \\
Hungary & 6 & 1.7 \\
Brazil & 5 & 1.5 \\
India & 5 & 1.5 \\
Japan & 4 & 1.2 \\
Romania & 4 & 1.2 \\
Austria & 3 & 0.9 \\
The Netherlands & 2 & 0.6 \\
Algeria & 1 & 0.3 \\
Italy, Argentina & 1 & 0.3 \\
Norway & 1 & 0.3 \\
Russia & 1 & 0.3 \\
Slovenia & 1 & 0.3 \\
UK, Singapore & 1 & 0.3 \\
Uruguay & 1 & 0.3 \\
USA, The Netherlands & 1 & 0.3 \\
Total & 344 & 100.0 \\
& &
\end{tabular}

Table I.

Geographic distribution of concept maps
12.5

6.7

5.8

2.6

2.6

2.6

2.3

1.7

1.5

1.5

1.2

1.2

0.9

0.6

0.3

0.3

0.3

0.3

0.3

0.3

0.3

100.0 
Authors with professorial duties dominated the production of concept maps, as might have been expected - indeed, as they dominate the domain. In ISKO proceedings 74 percent of the concept maps were produced by professors, in SIG/CR the figure was 63 percent. The combined distribution is shown in Table II; professors account for more than 70 percent of the concept maps altogether.

Nonparametric tests of independence were run using SPSS; results indicate the categories of country and occupational role occur with equal probabilities, and therefore the differences among them are statistically significant.

\subsection{Evaluative semiotic analysis}

All of the concept maps were subjected to content analysis to determine whether the "signs" represented in the concept maps could be attributed to either Peircian or Saussurian semiotic theory, or whether no semiotic construct was observed. For example, Figures 7 and 8 come from the same paper in ISKO9 (Afolabi and Thiery, 2006, p. 248,
Nodes and arcs

39

\begin{tabular}{lcr}
\hline Occupational role & Frequency & Percent \\
\hline Professor & 241 & 70.1 \\
Student & 51 & 14.8 \\
Practitioner & 37 & 10.8 \\
Professor and practitioner & 7 & 2.0 \\
Professor and student & 7 & 2.0 \\
& 1 & 0.3 \\
Total & 344 & 100.0
\end{tabular}

Table II.

Occupational roles of creators of concept maps

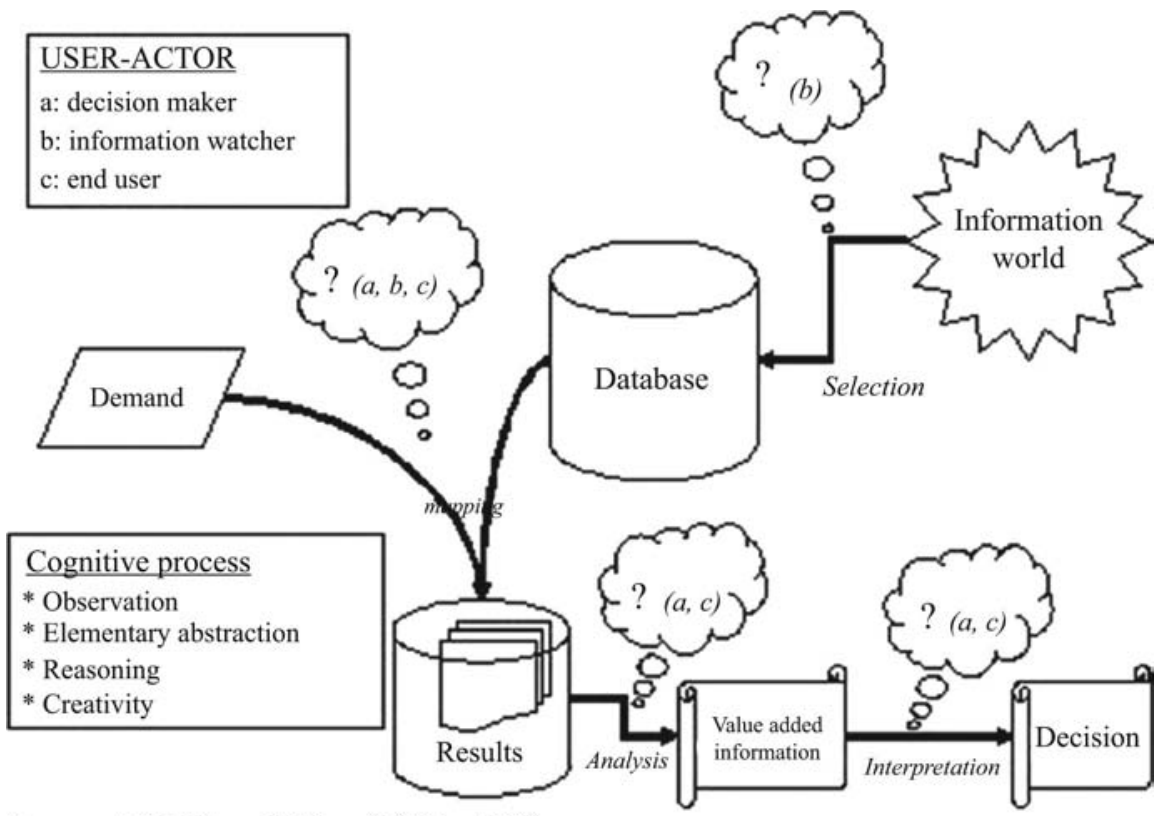

Source: Afolabit and Thiery (2006 p. 248)

Figure 7. Saussurian concept map "Architecture of an Economic Intelligence System" 


\section{JDOC 69,1}

Figure 8.

Peirceian concept map "The Use of Users' Expectation in an IS"
Figure 9.

Non-semiotic concept map: "Eidetic Description"

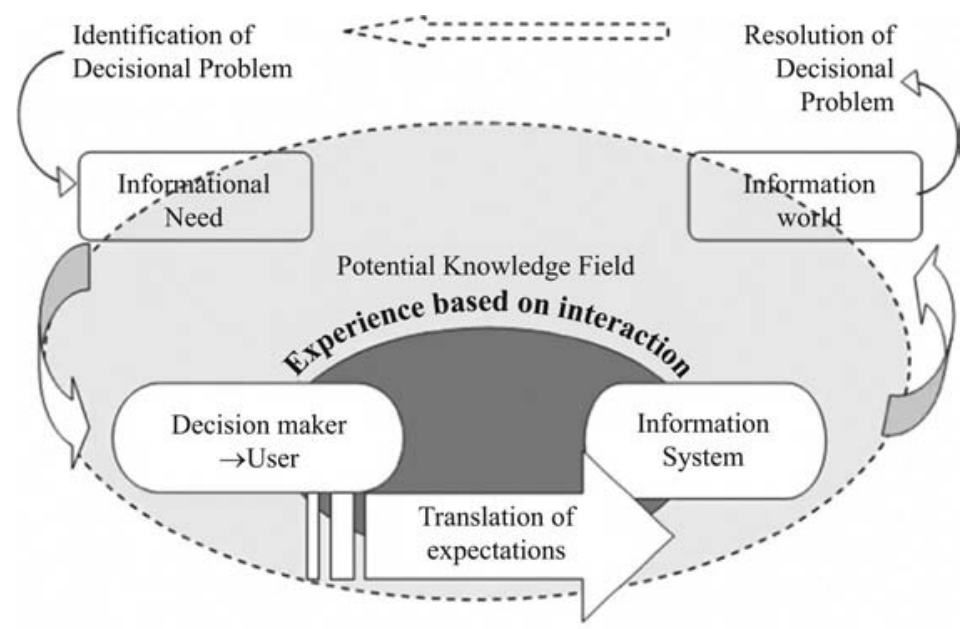

Source: Afolabi and Thiery (2006 p. 251)

p. 251). Figure 7 is an example of a Saussurian concept map, with central nodes "Result, Demand, Database, Information world, and Decision" and arcs "mapping, and selection."

The concepts represented in the map are static - signified and signifier. Figure 8 is an example of a Peircian concept map, with nodes "Potential Knowledge Field, Informational Need, and Information World" and arcs "Translation of expectations, Experience based on interaction, Identification of Decisional Problem, and Resolution of Decisional Problem." The concepts are dynamic, moving along the arcs from Representamen to Interpretant to Object at multiple dimensional levels, or, as Peirce might have said, from Firstness to Secondness to Thirdness.

Figure 9 is an example of a concept map that exhibits no semiotic theoretic. This map illustrates a single, static, concept, with only one node (eidetic description) and therefore, no arcs.

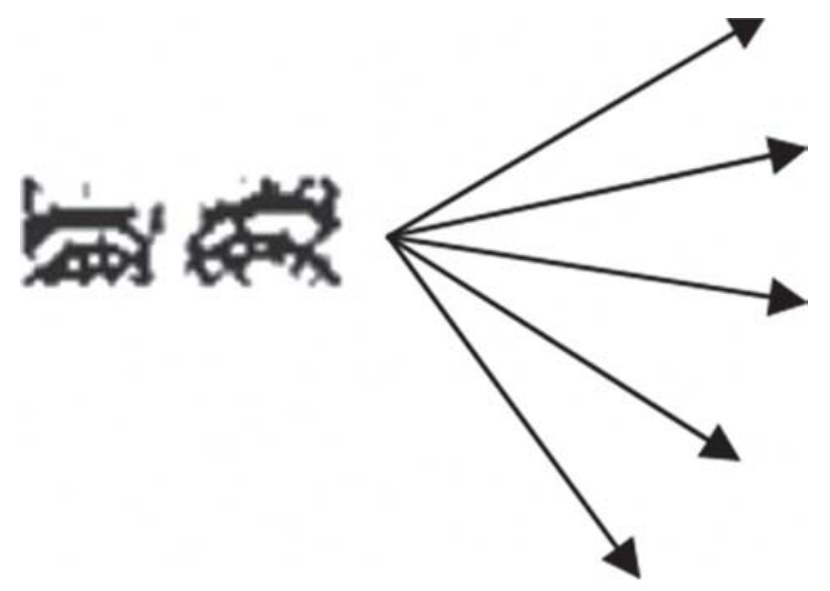

Source: Smiraglia (2008 p. 251) 
Roughly half of the concept maps were thus determined to display either Peirceian or Saussurian semiotic theory. Among the ISKO proceedings 48.1 percent were judged to display semiotic theory because they held observable "signs" serving as nodes with relationship arcs connecting them. Among the SIG/CR proceedings the proportion was 55.5 percent; the overall proportion of concept maps with semiotic theory visible was 50.9 percent. Among the concept maps with semiotic structures, Peirce's triadic theory predominated, found in 68.6 percent of all concept maps (in ISKO the proportion was 69.3 percent; in SIG/CR it was 67.6 percent). The demographic characteristics of the authors of these concept maps mirror those of the population at large. The largest proportion, 41.7 percent of semiotic concept maps, came from authors with USA affiliations, with much smaller proportions coming from France (14.3 percent), Germany (10.9 percent), and Canada ( 8 percent). Most authors were identified as professors (74.9 percent), with students generating 13.7 percent of the maps and practitioners 11.4 percent. Chi-squared tests of independence were not statistically significant for either country of origin or occupational role as influential on the presence or absence of semiotic theory. All concept maps with semiotic indications were analyzed separately. A nonparametric test of independence indicates the choice of Peirce or Saussure occurs with equal probabilities, and therefore the difference is statistically significant. But Chi-squared tests of independence were not statistically significant for either country of origin or occupational role as influential on the use of Peircian or Saussurian frameworks.

\subsection{Terms as signs in the concept maps}

We measured the "signs" (that is, the terms that represent the signs in the diagrams) found in the concept maps by applying Peirce's and Saussure's frameworks. These "signs" had to present the central point of the maps. We found 299 terms identifying "signs" as defined in Peirce's framework, and 161 using Saussure's. Under Peirce's triadic theory, the most-used term was "knowledge," appearing in 12 concept maps. This term constitutes 5.43 percent of all terms linked to "signs" in the maps. The second most-used term was "organization," which occurs in ten concept maps and represents 4.52 percent of the total terms found under Peirce's definition of "sign." The third most-used terms were "bibliographic" and "ontology," appearing in five maps each in both sets of proceedings, and representing 3.62 percent of total terms. "Sentence" was the fourth most-used term, at 2.01 percent. The highest-ranked map terms found using Saussure's framework are "system," "document," and "index," appearing in four maps each representing 2.86 percent of the total terms found. The second most-used terms were "ontology" and "theory," appearing in two maps each or 2.01 percent. These figures represent the raw counts of terms found in the concept maps.

To triangulate methodologically, the terms used to identify concepts at a meta-level were entered into WordStat software for analysis. In the first pass the terms were filtered using a taxonomy developed for domain analysis of ISKO proceedings (Smiraglia, 2011). The distribution of filtered concepts is illustrated in Table III.

The left columns show the distribution of terminology in the population at large, and the columns on the right show the distribution among the maps that were determined to have semiotic content. There are subtle differences apparent. First, the clusters are proportionately larger at the top of the distribution for the maps with 


\section{JDOC 69,1}

Taxonomic term (all maps)

Classification

Ontology

Concept

Thesaurus

Language

Type

Model

Table III.

Concepts filtered through ISKO conference taxonomy
Domain

Context

Entity

Organization
Taxonomic term

(semiotic maps)

Frequency as percent

User 18.7

Classification $\quad 12.0$

Thesaurus $\quad 9.3$

Language $\quad 8.0$

Model 8.0

Ontology 6.7

Context 5.3

Concept 4.0

Domain 4.0

Entity $\quad 4.0$

semiotic content, and categories such as "user," "thesaurus," and "model" rise to the top of the distribution, while more theoretical concept categories, such as "ontology" or "domain" fall farther down the distribution. This suggests a greater emphasis on applied knowledge organization among the concept maps with semiotic content.

In fact, there were 2012 terms used in all concept maps, of which 1,113 were unique, 417 were used twice, 173 were used three times, and only 52 were used more than five times. Among the concept maps with semiotic content there were many fewer terms 611, of which 435 were unique, 89 were used twice, 27 were used three times, and only 26 were used more than five times. These most-used terms appear in Table IV.

We have here evidence of the granularity of the domain, wherein over 2,000 terms appear as essential concepts in research papers but only 20 manage to occupy the top end of frequency distributions. Also, we have much more concentrated vocabulary among the concept maps with semiotic content, possibly because of a greater emphasis on applied knowledge organization.

WordStat's MDS capacity was used to create a three-dimensional map of the terms seen in these tables. This map appears in Figure 10. This map demonstrates the co-occurrence of terms in the concept maps, and the goodness of fit statistics are a bit extreme (high stress and low $R^{2}$ probably because of the low co-occurrence of terms in the maps in general. At any rate, the map presents a reasonable visualization of concepts in this population of $\mathrm{KO}$ concept maps.

Table IV.

Concepts external to the ISKO conference taxonomy

\begin{tabular}{lclc}
\hline Concept term (all maps) & $\begin{array}{c}\text { Frequency as } \\
\text { percent }\end{array}$ & $\begin{array}{l}\text { Concept term } \\
\text { (semiotic maps) }\end{array}$ & $\begin{array}{r}\text { Frequency as } \\
\text { percent }\end{array}$ \\
\hline Information & 1 & Work & 1.4 \\
Document & 0.9 & Document & 1.3 \\
Knowledge & 0.8 & Act & 1.3 \\
Text & 0.6 & Information & 1.2 \\
Act & 0.6 & Knowledge & 1.2 \\
Object & 0.5 & Individual & 1.1 \\
Index & 0.5 & Text & 1.1 \\
Work & 0.5 & Representation & 0.8 \\
Disc & 0.5 & Object & 0.7 \\
\hline
\end{tabular}




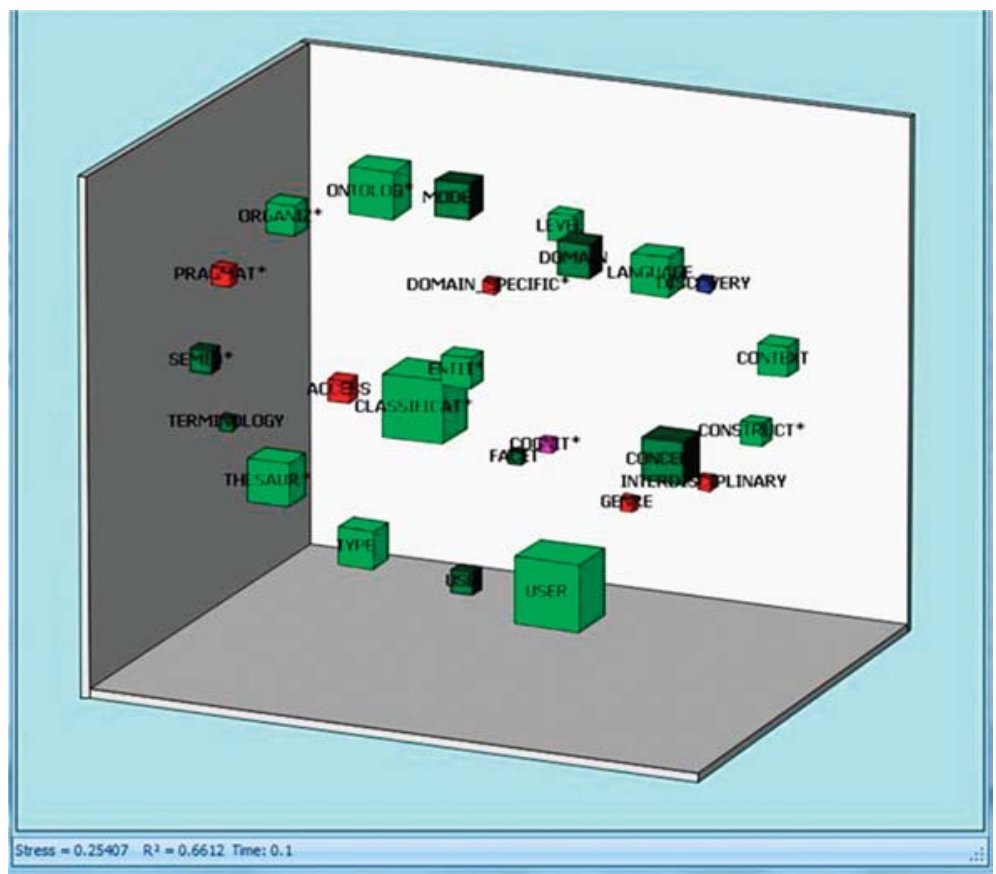

Nodes and arcs

In this visualization "classification" is at the center, with equidistant nodes occupied by "ontology" and "user" and "thesaurus." Domain-specificity, access, pragmatism, and interdisciplinarity form a cluster hovering just above the core. The remaining terms represent active components of the research front that are not quite core concepts.

An interesting question then arises: are all of the concepts represented in semiotic maps simple nouns, or are actions represented as well? As a matter of fact, only two "concepts" were expressed in verb form - "renting" and "bending." But, when the terms representing the arcs were analyzed, the majority of these were, in fact, actions. Concept terms represent the nodes in the concept maps; the arcs are represented differently, and the most frequently used node and arc terms from the semiotic concept maps are arrayed in Table $\mathrm{V}$.

Here we see the array of relationships represented by actions (mostly in verb form) which connect the nodes in the semiotic representations in $\mathrm{KO}$ concept maps. Whereas

\begin{tabular}{|c|c|c|c|c|}
\hline Node term & Frequency as percent & Arc term & Frequency as percent & \\
\hline Work & 1.4 & Act & 1.1 & \\
\hline Document & 1.3 & Class & 0.9 & \\
\hline Information & 1.2 & Contain & 0.6 & \\
\hline Knowledge & 1.2 & Express & 0.6 & \\
\hline Individual & 1.1 & Self & 0.6 & Table V. \\
\hline Text & 1.1 & Index & 0.6 & Node and arc terms in \\
\hline Representation & 0.8 & Analysis & 0.6 & semiotic concept maps \\
\hline
\end{tabular}




\section{JDOC 69,1}

\section{4}

central entities in the domain are works, documents, information, knowledge, and texts (reminiscent of Zins', 2007 knowledge map of information science), central activities of knowledge organization involve classing, containing, expressing, and indexing. While there are no particular surprises in this list, what is remarkable is the level of linguistic conformity present in the concept maps, acting here as a domain-analytic marker.

Finally, to compare the conceptual models of Peirceian concept maps to those of Saussurian concept maps, the taxonomic terms and nodal vocabularies were compared. These are shown in Table VI. Because there are fewer terms, and to increase clarity, proportions are not included in this representation.

The difference between the two semiotic approaches is subtle but still apparent in these distributions. Although the main emphasis is on users, there is slightly more emphasis on pragmatic applications (thesaurus, contexts) among the Saussurian vocabulary, and therefore slightly more emphasis on theoretical constructs (classification, model) among the Peirceian. There is less granularity in the Saussurian vocabulary. The Saussurian vocabulary clearly stems entirely from the concept of the "user," whereas in the Peirceian vocabulary "user" anchors a cluster alongside clusters anchored by "classification," "language," and "model." Where the "user" and "thesaurus" dominate the Saussurian vocabulary, "user," "classification," and "model" are roughly equivalent nodes in the more granular Peirceian vocabulary. The basic distinction between Peirceian and Saussurian semiosis is apparent in these concept maps.

The greater granularity seen in the Peirceian concept maps accords well with Peirce's own classification of firstness, secondness, and thirdness (see section 1.3 above). Anchor terms represent firstness - "User," "Classification," "Language," "Model." These terms are surrounded by terms representing secondness - some representing arguments, such as "Interdisciplinary," or "Discovery," some representing dicents, such as "Semantic," or "Pragmatic," and others representing rhemes "Ontology," or "Thesaurus." And on the outer edge are the iconic representations that represent thirdness: "Domain," and "Context," for example.

\section{Conclusion: what nodes and arcs tell us about knowledge organization as a domain}

We began this paper with a discussion about concepts and meaning. We set out to conduct this research so as to understand better the role of the "concept" in the domain of knowledge organization, where it is said to be of seminal importance. We hoped our content analysis of concept maps would reveal understanding about the domain and

Table VI.

Comparison of vocabulary in Peirceian and Saussurian concept maps

\begin{tabular}{llll}
\hline $\begin{array}{l}\text { Taxonomic term } \\
\text { (Peirceian) }\end{array}$ & $\begin{array}{l}\text { Node term } \\
\text { (Peirceian) }\end{array}$ & $\begin{array}{l}\text { Taxonomic term } \\
\text { (Saussurian) }\end{array}$ & $\begin{array}{l}\text { Node term } \\
\text { (Saussurian) }\end{array}$ \\
\hline User & Knowledge & User & Text \\
Classification & Document & Thesaurus & Work \\
Model & Information & Classification & Systems \\
Language & Work & Context & Document \\
Concept & Representation & Ontology & Process \\
Domain & Individual & Entity & Treaty \\
Ontology & Query & Type & Individual \\
Thesaurus & & Use & International
\end{tabular}


about its use of the "concept" as a seminal element. We analyzed 344 concept maps produced internationally over a period of 20 years. One might have expected chaotic results. Yet, in the main, we have seen evidence of a tightly-focused domain making essential use of its seminal theoretical constructs.

We found no influence of nationality or any other quantifiable variable on the use of concept maps or on their use as demonstrable visualizations of semiotic activity. Semiotics is essential to the domain of knowledge organization, because semiotic theories define the parameters of perception of "concepts." So in this finding of the absence of external influences, what we really uncover is evidence of a tightly focused domain. The authors creating research, reported at the research front in annual or biennial conferences, are tightly focused on advancing the domain of knowledge organization, which is based on a concept-theoretic (Dahlberg, 2006).

We also discovered two essential differences, both of which embrace the importance of semiotic theory for the domain of knowledge organization. First, the population of concept maps displays the same immense granularity as the rest of the domain. That is to say, each conference has some papers that are from the core theoretical base, exploring the intension of the domain; but each conference has more papers that push the boundaries of the domain, stretching the extension of the domain. The granularity found in concept vocabulary in the whole population of concept maps helps us to visualize this constant stretching of the domain. This is a healthy impetus for an evolving scholarly domain. But, the concept maps that demonstrate the use of semiotic theory (and make no mistake, we do not have any way to assert whether this is conscious, subconscious, or unconscious use of semiotic theory) - these concept maps use a much more tightly controlled vocabulary focused on the organization of knowledge that is useful for humans with information needs. The second essential difference is that between the concept maps that display Peirceian and Saussurian semiotic theories. The Peirceian maps are, at a meta-level, more theoretical in nature, used to demonstrate dynamic evolution along the traditional Peirceian perceptual triangle from Representamen and onward. The Saussurian maps use typically static semiotic approaches to visualize signifer and signified, but typically do not move beyond that map. Peirceian maps approach concepts a theoretical levels; Saussurian maps approach concepts at applied levels.

We also observed differences between the nodes and arcs in the semiotically-oriented concept maps. This suggests that the vocabulary of knowledge organization is even more structured than we might have imagined before. The nodes are represented by concept nouns; the relationship arcs among nodes are represented by action terms, usually verbs. Once again, this is as one might have expected it to be. But what is interesting here is the degree to which there is conformity across geographical, occupational, and chronological boundaries. This suggests that the domain of knowledge organization not only has a surprisingly sturdy core, but also that it is continually strengthened by the regular challenges to its extension posed by international conferences.

Hjørland (2002) has written about 11 approaches to domain analysis. We have uncovered a new approach. Arguably what we have done is simple content analysis. But in fact, we have grounded our content analysis of concept maps in the bibliometric domain by using Smiraglia's (2011) taxonomy as a vocabulary filter for comparing our data to bibliometric data about the domain. This methodology has yielded useful results for visualizing the domain of knowledge organization, and its use of its own central tenet, 
JDOC 69,1

the "concept." We suggest both further analysis of concept maps, and further use of semiotic filters for content analysis as means for domain analysis at large.

We wrote about the conference proceedings that made up our population earlier in the paper. Perhaps now is a good time to point out that the formal journal in the domain, Knowledge Organization, has for 37 years been a quarterly journal publishing 16-20 papers per year. Thus, the most vital venue for research in the domain has been, and continues to be conference proceedings. Most of the major work along the research front in knowledge organization is reported in these conferences. Despite the volatility that such a situation might suggest, we have discovered a surprisingly coherent, focused vocabulary of concepts, and an equally coherent and focused use of semiotics to visualize perception.

\section{References}

Afolabi, B. and Thiery, O. (2006), "Using users' expectations to adapt business intelligence systems”, in Budin, G., Swertz, C. and Mitgutsch, K. (Eds), Knowledge Organization and the Global Learning Society; Proceedings of the 9th ISKO International Conference, Vienna, July 4-7 2006, Ergon-Verlag, Würzburg, pp. 247-54.

Baker, E.L., Niemi, D., Navak, J. and Herl, H. (1991), "Hypertext as a strategy for teaching and assessing knowledge representation", paper presented at NATO Advanced Research Workshop in Instructional Design Models for Computer-Based Learning Environments, Enschede, The Netherlands.

Barthes, R. (1975), The Pleasure of the Text, Noonday Press, New York, NY, trans. by Richard Miller.

Buckland, M.K. (1997), “What is a document?”, Journal of the American Society for Information Science, Vol. 48 No. 9, pp. 804-9.

Chandler, D. (2004), Semiotics for Beginners, Routledge, Oxford.

Christiansen, P.V. (1988), Charles S. Peirce: Musten og mortel til en metafysik, IMFUFA, Roskilde.

Dahlberg, I. (2006), “Knowledge organization: a new science?”, Knowledge Organization, Vol. 33 No. 1, pp. 11-19.

Frege, G. (1892), "On concept and object”, originally published as "Über Begriff und Gegenstand”, in Vierteljahresschrift für wissenschaftliche Philosophie 16: S. 192-205, translated in Geach \& Black 1952, pp. 42-55.

Friedman, A. (2006), "Concept mapping a measurable sign", in Budin, G., Swertz, C. and Mitgutsch, K. (Eds), Knowledge Organization and the Global Learning Society; Proceedings of the 9th ISKO International Conference, Vienna, July 4-7 2006, Ergon-Verlag, Würzburg, pp. 130-1.

Friedman, A. and Thellefsen, M. (2011), "Concept theory and semiotics theory in knowledge organization”, Journal of Documentation, Vol. 67 No. 4, pp. 644-74.

Gaines, E. (2002), "Semiotic analysis of myth: a proposal for an applied methodogy", The American Journal of Semiotics, Vol. 17 No. 2, pp. 311-27.

Hjørland, B. (2002), "Domain analysis in information science: eleven approaches, traditional as well as innovative", Journal of Documentation, Vol. 58 No. 4, pp. 422-62.

Hjørland, B. (2009), "Concept theory", Journal of the American Society for Information Science and Technology, Vol. 60 No. 8, pp. 1519-36.

Hodge, G. (2000), "Systems of knowledge organization for digital libraries: beyond traditional authority files", Digital Library Federation, available at: www.diglib.org 
Kent, R.E. (2000), “The information flow foundation for conceptual knowledge organization", Dynamism and Stability in Knowledge Organization. Proceedings of the Sixth International ISKO Conference. Advances in Knowledge Organization, Vol. 7, Ergon Verlag, Würzburg, pp. 111-7.

Lambiotte, J.G., Dansereau, D.F., Cross, D.R. and Reynolds, S.B. (1984), "Multirelational semantic maps", Educational Psychology Review, Vol. 1 No. 4, pp. 331-67.

Mai, J.-E. (2001), "Semiotics and indexing: an analysis of the subject-indexing process", Journal of Documentation, Vol. 57 No. 5, pp. 591-622.

Margolis, E. and Laurence, S. (2005), “Concepts”, in Zalta, E.N. (Ed.), The Stanford Encyclopedia of Philosophy (Winter 2005 edition), available at: http://plato.stanford.edu/archives/ win2005/entries/concepts/

Novak, J.D. and Gowin, D.B. (1984), Learning How to Learn, Cambridge University Press, New York, NY.

Peacocke, C. (1999), Being Known, Clarendon Press, Oxford and New York.

Peirce, C.S. (1931-1958), "Collected papers of C.S. Peirce”, in Hartshore, C., Wesis, P. and Burks, A. (Eds), Harvard University Press, Cambridge, MA, 8 vols.

Peirce, C.S. (1998), "What is a sign?", in Houser, N. et al. (Eds), The Essential Peirce: Selected Philosophical Writings. Vol. 2 (1983-1913), Indiana University Press, Bloomington, IL, pp. 483-91.

Saussure, F.D. (1983), Course in General Linguistics, Roy Harris, Duckworth, London, (originally published in 1916).

Sebeok, T.A. (1994), Signs: An Introduction to Semiotics, University of Toronto Press, Toronto.

Silverman, K. (1983), The Subject of Semiotics, Oxford University Press, New York, NY.

Smiraglia, R.P. (2005), "Content metadata-an analysis of Etruscan artifacts in a museum of archeology”, Cataloging \& Classification Quarterly, Vol. 40 Nos 3/4, pp. 135-51.

Smiraglia, R.P. (2008), "Noesis: perception and everyday classification", in Arsenault, C. and Tennis, J. (Eds), Culture and Identity in Knowledge Organization: Proceedings of the 10th International ISKO Conference, Montréal, 5-8 August 2008. Advances in Knowledge Organization, Vol. 11, Ergon Verlag, Würzburg, pp. 249-53.

Smiraglia, R.P. (2011), "ISKO 11's diverse bookshelf: an editorial”, Knowledge Organization, Vol. 38, pp. 179-86.

Stock, W. (2010), "Concepts and semantic relations in information science", Journal of the American Society for Information Science and Technology, Vol. 61 No. 10, pp. 1951-69.

Tarski, A. (1995), Introduction to Logic and to the Methodology of Deductive Sciences, Dover Publications, New York, NY.

Thellefsen, M. (2004), "Concepts and terminology reflected from a LIS perspective: how do we reflect meanings of concepts?", Proceedings of the 12th Nordic Conference for Information and Documentation, September 1-3, 2004, Aalborg, Biblioteksarbejdes skriftsserie, pp. 68-75.

Thellefsen, M. (2006), "The dynamics of information representation and knowledge mediation", in Budin, G., Swertz, C. and Mitgutsch, K. (Eds), Knowledge Organization and the Global Learning Society; Proceedings of the 9th ISKO International Conference, Vienna, July 4-7 2006, Ergon-Verlag, Würzburg, pp. 279-86.

Webster's Dictionary (1984), New Riverside University Dictionary, The Riverside Publishing Company, Boston, MA. 
JDOC 69,1

Zins, C. (2007), "Knowledge map of information science", Journal of the American Society for Information Science and Technology, Vol. 58 No. 4, pp. 526-35.

\section{Further reading}

Bouissac, P. (1998), The Encyclopedia of Semiotics, Oxford University Press, New York, NY.

Hjørland, B. (2003), "Fundamentals of knowledge organization", Knowledge Organization, Vol. 30 No. 2, pp. 87-111.

Laurence, S. and Margolis, E. (2005), “Concepts”, Stanford Encyclopedia of Philosophy, Stanford University, Stanford, CA.

MacEachren, A.M. (2004), How Maps Work: Representation, Visualization, and Design, 2nd rev. ed., Guilford Press, New York, NY.

Peirce, C.S. (1931) in Hartshorne, C. and Weiss, P. (Eds), Collected Papers of Charles Sanders Peirce Vol. 4, Harvard University Press, Cambridge, MA.

Radford, G.P. and Radford, M.L. (2004), "Structuralism, post-structuralism, and the library: de Saussure and Foucault", Journal of Documentation, Vol. 61 No. 1, pp. 60-78.

Smiraglia, R.P. (2001), The Nature of "A Work”: Implications for Organization of Knowledge, Scarecrow Press, Lanham, MD.

Smiraglia, R.P. (2002), "The progress of theory in knowledge organization", Library Trends, Vol. 50 No. 3, pp. 300-49.

Thellefsen, M. (2003), "The role of special language in relation to knowledge organization", Proceedings of the American Society for Information Science and Technology, 66th Annual Meeting, Vol. 40, pp. 206-12, October.

\section{About the authors}

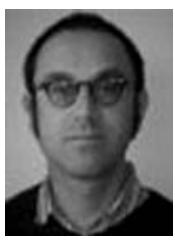

Alon Friedman, $\mathrm{PhD}$ is currently teaching in the NYC area and working as Data Analyst and Programmer. Alon Friedman is the corresponding author and can be contacted at: dr.alon.friedman@gmail.com

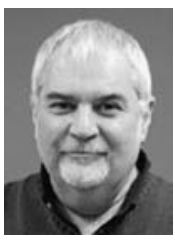

Richard P. Smiraglia (PhD, University of Chicago, 1992) is Professor, Information Organization Research Group, School of Information Studies, University of Wisconsin, Milwaukee. He brings empirical epistemology to the problems of the order and structure of recorded knowledge, and is an expert in the phenomenon of instantiation among information.

To purchase reprints of this article please e-mail: reprints@emeraldinsight.com Or visit our web site for further details: www.emeraldinsight.com/reprints 